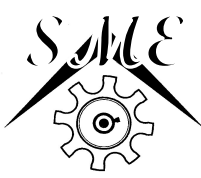

ESTD 2005

\title{
A STUDY ON IMPORTANCE OF QUALITY FUNCTION DEPLOYMENT IN THE HOSPITAL SECTOR
}

\author{
*Krishna das $M^{1}$, Vinoth Kumar $M^{1}$ and Pramod $V^{2}$
}

${ }^{1}$ Department of Mechanical Engineering, Hindustan Institute of Technology and Science, Kelambakkam, Tamil Nadu-603103, India ${ }^{2}$ Department of Mechanical Engineering, NSS College of Engineering, Palakkad, Kerala-678008, India

\begin{abstract}
To sustain a healthy society, hospitals play a vital role and are considered a significant player in maintaining the happiness of the people in every nation. In this paper, an attempt has been made to highlight the importance of Quality Function Deployment (QFD) in the health care industry. QFD is a technique adopted and implemented in various industries. The primary purpose is to translate customer voice into technical language. The components of the House of Quality matrix are briefed, which can be easily understood and follow. The practicality of each component has to be studied. The implementation approach is suggested, and the outcome can be visualized as continuous improvement in customer satisfaction. The decision-makers get a clear awareness about their strengths, weaknesses, opportunities and threats (SWOT). A clear understanding of the technical correlations help the toplevel managers to implement QFD in a smooth manner
\end{abstract}

Keywords: Quality Function Deployment (QFD), House of quality (HoQ), Voice of customer (VoC) and Voice of organization $(\mathrm{VoB})$

\section{Introduction}

Over the years, hospitals have adopted various quality tools and methods to improve the efficiency of their services. Identifying the right tool and following the proper methodology is very important to maintain any quality improvement effort. It is valid for healthcare organizations also. This paper is about how Quality Function Deployment (QFD) can be used to understand customer requirements, prioritize organizational goals and fetch maximum benefits from the available resources.

\section{Evolution of CFD}

QFD approach was developed in Japan in the 1960s. The aim was to understand the various needs of customers and design high quality engineered products to provide high value to customers. In 1970, Mitsubishi Heavy Industries demonstrated the positive impacts of QFD on the world. According to Akao, QFD is a method to develop a design quality aimed at satisfying the consumer and then translating the consumer demand into design targets and major quality assurance points which can be used throughout the production phase. QFD can assure the quality of design even though the product is still in the design stage. The main objectives behind implementing CFD are,

*Corresponding Author - E- mail: kriskd123@gmail.com i. Prioritizing spoken and unspoken customer needs

ii. Translating these needs into technical specifications

iii. To build and deliver a quality product or service by aiming towards customer satisfaction

QFD focuses on the following areas - product planning, part development, process planning, production planning and services planning. Over the years, many organizations have implemented QFD and have reaped benefits from it. Today, the use of QFD is not just limited to production or manufacturing organizations. Service industries have benefitted from this approach. QFD is now an integral part of several quality improvement methodologies like lean six-sigma. Healthcare organizations such as hospitals have adopted many tools to improve efficiency enhancement, including those practised in manufacturing industries. Studies show that healthcare organizations have benefitted immensely from the adoption of quality practices from other industries.

\section{Benefits of QFD}

It has been proved that QFD is an effective tool for various types of organizations. QFD is a rigorous approach to understanding customer requirements and translating those requirements into product or service 
features, thus satisfying customer needs. It helps in providing the right direction to the organization needs.

\section{Components of CFD}

House of quality is the widely used approach of QFD. It resembles the shape of a house; thus, the tool is popularly called the House of Quality. It is a matrix that helps prioritize customer needs based on their perceived value and match those against how an organization can meet those requirements. The house of quality consists of the following components
Voice of the customer - VoC
Voice of the Business - VoB
Interrelationship matrix
Technical matrix
Technical correlations
Planning matrix

\subsection{Voice of the customer}

The left side of the house shows customer requirements. In other words, it means what the customers ask for in a product or service. Primary customer requirements are supported by secondary requirements to represent the primary needs in a detailed manner.

\subsection{Voice of the Business}

The ceiling of the HoQ represents the voice of the business or technical descriptors. It represents a set of tools and methods by which the organization is willing to meet the customer requirements. Further definition of the primary technical descriptors is achieved by defining a list of secondary technical descriptors representing the primary technical descriptors in a much-detailed way.

\subsection{Interrelationship matrix}

The relationship between customer requirements and the technical descriptors are represented in the interior walls of the house. The relationship matrix represents the degree of influence between each technical descriptor and specific customer requirement in a graphical way.

\section{Technical matrix}

The technical descriptors which are prioritized are shown in the foundation of the house. The prioritization is based on benchmarking, degree of technical difficulty and the listed target value.

\section{Technical correlations}

It refers to how the technical descriptors influence each other, which represents the roof of the matrix. It helps to identify similar technical descriptors which have a positive or negative impact on the technical descriptors, which might adversely impact the planning process

\section{Planning matrix}

It represents prioritized customer requirements. The customer requirements are prioritized based on several factors, including importance to th customer, target value, scale-up factor, sales point and absolute weight.

\section{QFD in a healthcare organization}

\subsection{The Problem}

The routine health checking department of the hospital had been receiving several customer complaints, which made the overall satisfaction index low. The visitors, who were supposed to be asymptomatic, have different needs from patients who visited the hospital for specific treatments. The measures taken by the organization had not resulted in any significant improvement.

\subsection{The approach}

The management decided to carry out a study based on the QFD approach to understand people who visited the preventive health department. The study was carried over for two months. The organization followed various methods like reviewing customer feedback forms, observing customer behaviour, structured interviews with 50 per cent of the total visitors. The customers were asked to rate the various parameters based on their perceived value and how they rate the service characteristics. Several brainstorming sessions were also carried out by the organization to identify the technical descriptors. Each customer requirement was thoroughly examined to understand how it has been correlated with the technical descriptors. A target value was set for each customer requirement. For the technical descriptors, a similar approach was followed. The requirements of customers were prioritized based on the target value, scale of factor and sales point.

Similarly, the technical descriptors/business requirements were prioritized based on technical difficulty, target value, absolute weight and relative weight.

\section{Result}

By completing a comprehensive analysis of customer requirements and the technical descriptors, the organization will be in a position to prioritize its actions. The organization can implement the recommendations in high priority areas. In the next few months, a steady 


\section{Journal of Manufacturing Engineering, June 2021, Vol. 16, Issue. 2, pp 048-050}

improvement in the customer satisfaction index can be recorded.

\section{Conclusion}

Organizations should prioritize the requirements which can have maximum impact on the outcome. Managers need to identify the right approach to solve a problem, keeping a proper balance between the available resources and the target requirements. QFD is an effective tool to prioritize decisions.

\section{References}

1. Barnett, W.D., Raja, M.K.,(1995.), Application of QFD to the software development process. International Journal of Quality and Reliability Management 12 (6), 24-42.

2. Pramod V.R, Devadasan S.R and Jagathi Raj V.P. (2006), Customer voice adoption for maintenance quality improvement through MQFD and its analysis. International journal management practice, volume 2, No 2 ,

3. Valentin, E. K., (2001) "SWOT Analysis from a ResourceBased View," Journal of Marketing Theory and Practice, Vol. 9, spring, pp. 54-68,

4. Akao Yoji, Ohfuji Tadashi(1989) "Resent Aspect of Quality Function Deployment in Japan", Proceedings of International Conference for Quality Control-1987. Tokyo, JUSE and IAQ.pp17-26

5. Akao Yoji.(1990). Introduction to quality Deployment Application Manuel of Quality function Deployment (In Japanese) JUSE Press.
6. Akao, Yoji. (Ed.), 1990a. Quality Function Deployment: Integrating Customer Requirements into Product Design. Productivity Press, Cambridge, MA.

7. Bahill, A.T., Chapman, W.L., (1993) A tutorial on quality function deployment. Engineering Management Journal 5 (3), 24-35.

8. Bossert, J.L., (1991) Quality Function Deployment: A Practitioners Approach. ASQC Quality Press, Milwaukee, WI.

9. Bosserman, S,( 1992). Quality Function Deployment: The Competitive Advantage. Private Trunked Systems Division, Motorola

10. Chan, L.K., Wu, M.L., (1998). Prioritizing the technical measures in quality function deployment. Quality Engineering 10 (3), 467-479.

11. Farrell Jr., R., (1994) Quality function deployment: Helping business identify and integrate the voice of the customer. Industrial Engineering 26 (10), 44-45.

12. Franceschini, F., Rossetto, S., (1998) Quality function deployment: How to improve its use. Total Quality Management 9 (6), 491-500.

13. Nichols, K., Flanagan, D., (1994) Customer-driven designs through QFD. World-Class Design to Manufacture 1 (6), $12-19$.

14. Pheng, L.S., Yeap, L., (2001) Quality function deployment in design/build projects. Journal of Architectural Engineering 7 (2), 30-39.

15. Davy George Valavi, V.R. Pramod (2015) A hybrid fuzzy MCDM approach to maintenance Quality Function Deployment. Decision Science Letters 4 97-108 